\title{
Conf $760727-1$
}

LA-LiR -76-1445

TITLE: Colculations of Haves Formed from Surface Cavities

AUTIIOR(S): Charles L. Mader

SUBMITTED TO: Coastal Engineering Research Council

By arecptanre of thlo article for publication. the publisher rrcosinleet the Government's (licenac) righte in any copyright and the $G$ svernment and its euthurized representulven have unreutricied rizht to reproduce in whole or in part eaid article under ans copyright coeured by the publisher.

The Lox Alamos Selentific Luboratory rrquestu that the publinher ideniofs this article as work performed under the ausplete of the UStiRDA.

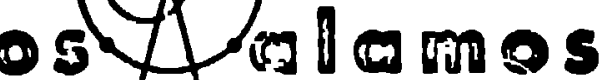

sciontivio laboratory of the University of California los alamos. NEW MEXICO B7545<smiles>C[13CH][13CH][13CH]</smiles>

An Allirmotive Action/Equal Opporlunnly Employee

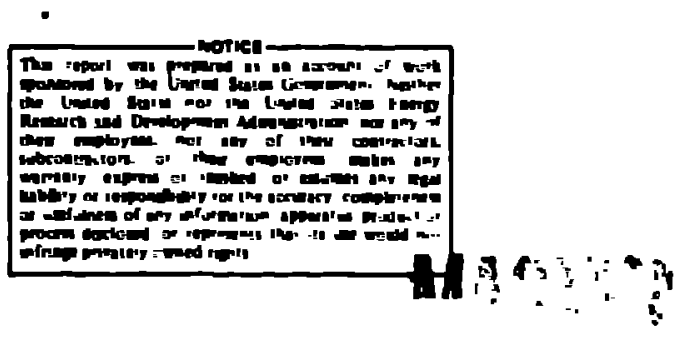

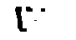

INITHA STATIS

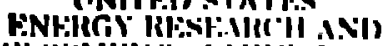

Mum Nin mi

insing

6

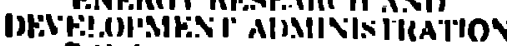




\title{
CALCULATIONS OF HAVES FORIED FROH SURFACE CAVITIES \\ Charles L. Mader* .
}

\begin{abstract}
AESTRACT
The wave motion resulting from cavities in the ocean surface was Investigated using both the long wave, shallow water model and the incompressible Navier-Stokes equations. The fluid flow resulting from the calculated collapse of the cavities is significantly different for the two models. The experimentally observed flow resulting from explosively formed cavitles is in better agreement with the flow calculated using the incompressible Navier-Stokes model. The resulting wave motfons decay rapldly to deep water waves. Large cavities located under the surface of the ocean will be more likely to result in Tsunami waves than cavities on the surface. This is contrary to what has been suggested by the upper critical depth phenomenon.
\end{abstract}

\section{INTRODUCTION}

The prediction of water waves generated by large-yleld exp? ostons has been based on extrapolation of empirical correlations of smallyleld experimental data, usually assuming the waves were shallow water waves. Because the accuracy of such predictions is questionable, the need exists for a detalled description of the mechanism by which viaves are generated by explosions. In particular the "upper critical depth" phenomenon needs to be understood. The upper critical depth phenomenon is an experimentally observed wave height maximum that occurs when an explosive charge is approximately two-thirds submerged. The observed height at the upper critical depth is twice that observed for completely submerged explosive charges. If the waves formed are shallow water waves capable of forming Tsunamis, then the upper critical depth phenomenon is important to evaluating the probability of a Tsunami event from other than tectonic events.

Theoretical evaluatiun of the early interaction of the detonation products of an explosive charge wtth the water and air interfaces and the resulting wave profile near the detonation has been performed by Mader ${ }^{1}$ using the multicomponent reactive conipressible hydrodynamic code 2DE. 2 The pressure and velocity contours for the early interaction of the explosive with the water and air are shown in Fig. 1. The initial formation of the lip or splash wave on the water cavity is also numerically described and it has been suggested that the concentration of momentum near the water surface in the splash wave is a contributing

Theoretical Division, Los Alanios Sctentific Laboratory, University of Callfornia, Los Alamos. New Mexico 87545 
factor in the upper critical depth phenomenon, rcsulting in a bubble cavity radius about the same as if the explosive bubble was completely confined by water. The high velocity present in the splash wave is a result of the initial water shock being quickly rarefled and permitting a second shock to be delivered from the explosive products. Subsequent shocks and rarefactions occur while the detonation products have high pressure. Each reverberation increases the particle velccity of the splash vave by an increment that decreases as the pressure of the driving detonation products decreases. The perticle velocity of the remainder of the viater cannot be increased by reverberations during the early high pressure motion because a free interface is not present. The consequence of this complicated interaction is that the maximum bubble radius achieved by a partially submerged explosive charge is slightly larger than one would expect to observe if the explosive sphere and its bubble was confined by water at one bar.

The bubble is observed to increase to a maximum radius of about 0.5 meter in 0.2 second and then take about 0.3 second to collapse as described in Refs. 1 and 3 for a $1.27-\mathrm{cm}$ radius 9404 explosive sphere initiated at the center and immersed to a depth of $1.59 \mathrm{~cm}$.

In this paper we shall describe an investigation of the flow after the cavity reaches its maximum dimensions. We assume that the flow is essentially incompressible at the times of interest and that the surrounding fluid is approximately at rest at maximum bubble radius.

The waves observed by $\mathrm{Craig}^{3}$ from the collapse of the bubble resulted in a train of waves moving at about 1.25 meters/second with a one-meter wavelength. Hass markers located one meter below the water surface and markers lacated half a meter below the surface and one meter from the explosive did not show any appreciable movement conipared with those located nearer the surface or explusive charge. This result suggests that the fluid flow will not be well described by the usual shallow water-long wave model.

We have calculated the fluid dynamics of a cavity initially 0.5 meter in radius with and without a lip, using a shallow water long wave model and a model based upon the incompressible Navier-Stokes equations.

\section{SHALLOW WATER, LONG WAVE MODEL}

The long wave theory applies when the depth relative to the wavelength is small, and when the vertical component of the motion does not influence the pressure distribution, which is assumed to be hydrostatic. It is appropriate for Tsunami wave foriation, propagation and early shoaling behavior as described in Ref. 4. The Slifll code described in Ref. 4 was modified to solve the long wave equations using an improved numerical difference technique.

The long wave equations solved by the SWAN code are: 


$$
\begin{gathered}
\frac{\partial U}{\partial t}+U \frac{\partial U}{\partial X}+V \frac{\partial U}{\partial Y}+g \frac{\partial H}{\partial X}=F V+F(x)-g \frac{U\left(U^{2}+V^{2}\right)^{1 / 2}}{C^{2}(D+H)} \\
\frac{\partial V}{\partial t}+U \frac{\partial V}{\partial X}+V \frac{\partial V}{\partial Y}+g \frac{\partial H}{\partial Y}=F U+F(y)-g \frac{U\left(U^{2}+V^{2}\right)^{1 / 2}}{C^{2}(D+H)} \\
\frac{\partial H}{\partial t}+\frac{\partial(D+H-R) U}{\partial X}+\frac{\partial(D+H-R j V}{\partial Y}-\frac{\partial R}{\partial t}=0
\end{gathered}
$$

where $U=$ velocity in $X$ direction ( $i$ index)

$V=$ velocity in $Y$ direction ( $j$ index)

$g$ = gravitational acceleration

$t=$ time ( $n$ index)

$H$ - wave height above mean water level

$R=$ bottom motion

$F=$ Coriol is forçe parameter

$C=$ coefficient of DeChezy for bottom stress

$F(x), F(y)=\begin{aligned} & \text { forcing functions of wind stress and barometric } \\ & \text { pressure in } Y \text { and } Y \text { direction }\end{aligned}$
$D=$ depth.

To obtain stable numerical solutions, the fintte difference equations must not have negative diffusion. The following difference equations are stable but require shat the time step be kept near the maximum or the numerical results will become smeared. C. W. Hirts suggested this approach when the difference equations described in Ref. 4 were found to be unstable in certain directions of the flow.

The wave height $H$ and depth $D$ are taken as cell centered and the velocities are centere'i at cell boundaries. The difference equations at each time step are in order:

$$
\begin{aligned}
H_{i, j}^{n+1}= & H_{1, j}^{n}-\Delta t\left[\frac{U_{i+1, j}^{n}}{\Delta x}(T D 1)-\frac{U_{i, j}^{n}}{\Delta x}(T D 2)+\frac{V_{1}^{n}, j+1}{\Delta y}(T V 1)-\frac{V_{1, j}^{n}}{\Delta y}(T V 2)\right] \\
& +R_{1, j}^{n+1}-R_{1, j}^{n} \\
& T D 1=D_{i+1, j}+H_{i+1, j}^{n}-R_{i+1, j}^{n}\left(U_{i+1, j}<0\right)
\end{aligned}
$$




$$
\begin{aligned}
& T 02-D_{1, j}+H_{i, j}^{n}-R_{1, j}^{n}\left(U_{i, j}<0\right) \\
& T W=D_{1, j+1}+H_{1, j+1}^{n}-R_{1, j+1}^{n}\left(V_{1, j+1} \leq 0\right) \\
& \text { TV2 }-D_{1, j}+H_{1, j}^{n}-R_{1, j}^{n}\left(V_{1, j}<0\right) \\
& T D 1=D_{i, j}+H_{i, j}^{n}-R_{i, j}^{n}\left(U_{i+1, j}>0\right) \\
& T D 2=D_{i-1, j}+H_{i-1}^{n}-R_{i-1, j}^{n}\left(U_{i, j}>0\right) \\
& T V 1=D_{1, j}+H_{1, j}^{n}-R_{f, j}^{n}\left(V_{1, j+1}>0\right) \\
& T V 2=D_{1, j-1}+H_{f, j-1}^{n}-R_{f, j-1}^{n}\left(V_{f, j}>0\right) \\
& v_{i, j}^{n+1}=v_{i, j}^{n}=\Delta t\left[\frac{U_{1, j}}{\Delta x}(T U 1)+\frac{T V}{\Delta Y}(T U 2)\right]-g \frac{\Delta t}{\Delta x}[T H U] \\
& +\Delta t\left\{-F V_{i, j}^{n}-F_{i, j}^{(x)}+s_{i, j}^{B}\right\} \\
& T V=0.25\left(v_{1, j}+v_{1, j+1}+v_{1-1, j+1}+v_{1-1, j}\right) \\
& T U 1=v_{i+1, j}-v_{1, j}\left(v_{1, j}<0\right) \\
& T U 2=U_{1, j+1}-U_{1, j}(T V<0) \\
& T U 1=v_{i, J}-U_{i-1, j}\left(U_{i, j}>0\right) \\
& T U_{2}=U_{1, j}=U_{1, j-1}\left(T V_{>}>0\right) \\
& T N U=H_{1, j}-H_{1-1, j}
\end{aligned}
$$




$$
\begin{aligned}
& v_{1, j}^{n+1}=v_{1, j}^{n}-\Delta t\left[\frac{T U}{\Delta x}(T V I)+\frac{v_{1, j}}{\Delta t}(T V 2)\right]-g \frac{\Delta t}{\Delta T}[T r V] \\
& +\Delta t\left\{F U_{i, j}^{n}-F(y)+s_{1, j}^{B}\right\} \\
& T U=0.25\left(U_{1, j}+u_{i+1, j}+U_{1, j-1}+U_{i+1, j-1}\right) \\
& T V I=V_{1+1, j}-V_{1, j}(T U<0) \\
& T 2=v_{1, j+1}-v_{1,}\left(v_{1, j}<0\right) \\
& \left.T V)=V_{1, J}-V_{1-1, J}(\pi)>0\right) \\
& T v_{2}=v_{1, J}-v_{1, J-1}\left(v_{1, j}>0\right) \\
& \pi N=\|_{1, j}-H_{1, j-1}
\end{aligned}
$$

and

$$
s_{1, j}^{B}=g u_{1, j}^{n}\left(\overline{u_{1, j}^{n}}+\overline{v_{1, j}^{n}}\right)^{1 / 2} / c^{2}\left(n_{1, j}+u_{1, j}^{n}\right)
$$

The calculations were perforned with 69 cells in the $X$ direction and 130 cells in the $Y$ direction. The cells wre .06 meters square and the tiac step was 0.001 seconds. The gravity constant was $-9.8 \mathrm{~m} \mathrm{sec}-2$. Although the problew described in this report was symmetrical and required only one direction, the calculations descritbed were perfonmed with the toro dimenstonal Sidsl code.

The computed wave proftles using the shallot water equations in the SWN code for the collapse of 0.5 -meter radius hole are show in Fig. 2 and for the collaiss of a 0.5 -neter radius hole with 0.25 neter high and 0.50-meter wide triangul, 11 p (which approximates the experimentally observed bubble profile) are shown in Figs. 2 and 4 . Figurn 4 also shows the velocity in the $Y$ direction. The Initial whter depth ws three meters.

\section{IICOIPRCSSIBLE MAVICR-STOKES IDOEL}

The farker and Cell (IMC) method of Marlow and Heleh" is a muertcal technique for calculation of viscous, Incompressible flow with a free surface. 
The method uses a finite-difference technique for solving the timedependent Havier-Stokes equations.

These equations for two-dimensional flows are

$$
\begin{aligned}
& \frac{\partial U}{\partial X}+\frac{\partial V}{\partial Y}=0 \\
& \frac{\partial U}{\partial t}+\frac{\partial U^{2}}{\partial X}+\frac{\partial U V}{\partial Y}=-\frac{\partial \phi}{\partial X}+g_{X}+v\left(\frac{\partial^{2} U}{\partial X^{2}}+\frac{\partial^{2} U}{\partial Y^{2}}\right) \\
& \frac{\partial V}{\partial t}+\frac{\partial U V}{\partial X}+\frac{\partial V^{2}}{\partial Y}=-\frac{\partial \phi}{\partial Y}+g_{Y}+v\left(\frac{\partial^{2} V}{\partial X^{2}}+\frac{\partial^{2} V}{\partial Y^{2}}\right)
\end{aligned}
$$

where $\phi$ is the ratio of pressure to constant density, gy arc gy are the $X$ and $Y$ components of body acceleration, and $v$ is the kinematic viscosity coefficient. The MAC method is based on an Eulerian network of rectangular cells, with velocities centered at cell bourdarles and the pressure cell-centered. Just as the differential equations of motion are statements $O_{i}{ }^{\circ}$ the conservation of mass and momentum, the $M M C$ finite-difference equations express these conservation principles for each cell, or combination of cells, in the computing mesh.

After the introduction of MAC, much attention was given to devisIng more accurate treatments of the free surface boundary conditions. Chan and Street ${ }^{7}$ developed a technique for more accurate del ineation of the free surface. This permitted the free surface pressure to be specified at the surface Itself, rether than at the center of the surface cell. Nichols and Hirt "modif'ed the Chan and Strcet procedure, devising a technique for defining the fluid surface by a set of surface marker particles that move with local fluid velocity. These particles allow surface-cell pressures in iAC to be arcuratcly specified by means of linear interpolation or extrapolation betiveen the knowri values of pressure in the nearest full cell and the Jesired fluid surface.

A Sim. ified :AAC (SIAC) has been described by Harlow and Amsden.' The SiUC technique has bean modified to include the Hichols and Hirt free surface treatinent. The computing program used for the calculations is called ZUHI and is deseribed by Nosden. ${ }^{10}$ The calculatir.rir. ive performed with 100 cells in the $X$ direction and 60 cells $i$. . Y direction. The cells were 0.05 meters square and the time step incremant was 0.0003 seconis. The convergence criterion is the maximum permitted change in pressure from hydrostatic pressure in any cell between iteration steps diviced by the sum of the changes at t:vo iteration steps and was 0.01 . Three or more surface particles were used in each cell. The gravity constant vias $-9.8 \mathrm{~m} \mathrm{sec}^{2}$. The viscosity coefficient was $0.01 \mathrm{gm} \mathrm{sec}^{-1} \mathrm{~m}^{-1}$. Prel iminary calculations shoved that the results were independent of whether the water depth was 3.0 or 1.5 meters; therefore in the calculations presented in this paper the cavity was in 
water initially 1.5 meters deep. The wave amplitude at late times and the details of the bubble collapse after first collapse and jetting were sensitive to the amount of viscosity used in the calculation so the value chosen was the smallest that would also permit numerically stable results. The computed wave profiles using the ZUNI code to solve the incompressible llavier-Stokes equations for the collapse of a 0.5 -meter radius hole with a 0.25 -meter high and 0.5 -meter wide triangular lip are shown in Fig. 5.

\section{COMPARISONS}

The experimental and calculated wave parameters are summarized in Table 1. The experimental wave parameters are given for the first three waves after four neters of travel fron the center of the explosive charge. The calculated wave parameters for the Airy wave were calculated using the WAVE code" for a cepth of three meters and using the experimentally observed wave height and wave length. Since the : roup velocity is almost exactly half the wave velocity, the Airy wave is a deep water wave. The deep water Airy wave is a good approximation to the experimentally observed wave.

The collapse of the cavity is quite different between the SHAN and ZUNI calculation as shown in Figs. 3 and 5 . The shallovi water cavity calculation collapses from the side in less than 0.1 second while the Havier-Stokes cavity calculation collapses from the botion in about 0.5 seconds. The experimentally observed bubble collapses approximately symmetrically frori the bottom in about 0.3 seconds, so the llavierstokes calculation is a more realistic description of the observed flow.

As shown in Table I the Navier-Stokes calculation results in wave pirameters more closely" appruximating those observed experinientally than thcse calculated using the shallow water theory. The waves calculated using the incompressible ilavier-Stokes equations have conplicated wave patterns and the waves quickly decay into deep water waves witin the particle motion rapidly decreasing with increasing depth below the water surface. This is also in agreenent with the experimental observations of mass markers described in the introduction.

TABLE I

CALCULATED AND EXPERIHENTAL WAVE PARAHETERS

\begin{tabular}{|c|c|c|c|c|}
\hline & Experimental* & Airy Wave & Shallow & Navier-Stokes \\
\hline Wave Velocity $(\mathrm{m} / \mathrm{s})$ & $1.25 \pm 0.1$ & 1.2489 & 5.42 & $1.50 \pm 0.50$ \\
\hline Amplitude (cm) & $1,1.8,2.5$ & 2. $\therefore$ (input) & 10.1 & $<4.0$ \\
\hline Wave Length $(m)$ & $1.5,1.0,1.0$ & 1.0 (input) & 1.0 & 1.0 \\
\hline Period (s) & $1.2,0.8,0.8$ & 0.8007 & 0.18 & $0.66_{-0.2}^{+0.3}$ \\
\hline Group Velocity (ii/s) & & 0.6244 & & \\
\hline
\end{tabular}

First three waves observed. 


\section{v. CONCLUSIOHS}

The experimentally observed waves from the cavities formed by explosions near the water surface are better reproduced by models solving the incompressible ilavier-Stokes equations than by models solving the shallow water, long wave equations. The experimontally otserved waves are deep water waves and the ohserved upoer critical depth phenonenon is apparently a result of a partition of energy near the water surface which results in high amplitude deep water waves (of high potential and low kinetic energy) and not the shallow water waves required for Tsunamis. As the explosive is detonated inder the water surface, more of the energy is imparted to the water resulting in waves that have smaller amplituce but more of the enerqy is present in the water as kinetic energy rather than putential energy. The waves fomed will more closely resemble shallow water waves and will not disperse as rapidly as waves formed from surface detonation.

The upper critisal depth phenomenon is apparently not important to the formation of Tsunami waves. Large cavities located under the surface of the ocean will be more likely to result in shallots water Tsunani waves than cavities on the surface. A cavity would have to be quite large and reach very deep into the ocean before it could be an effective agent for forming significant Tsunami waves.

To obtain a more realistic solution to the problem of wave fomation from explosions one would need to follow the hydredynamics from the early compressitle to late incompressible stages with one of the inflicit continuous iluid methods currently under developrent. of particular interes: :nul: be to determine the source and significance for wave formation of the water jet and root experimentally orserved tefore the explosive bubu.e reaches maximum radtus at depths similar to the upper critical depth.

\section{ACKNOIILEDGIANTS}

The author gratefully icknowledges the contritutions of $\dot{A}$. A. Ansden, F. H. Harlow, B. D. Michols, T. D. Butler, C. H. Hirt, and K. H. Olsen of the LOS Alarios Scientific Laboratory, of G. R. Matller, H. G. Loomis, and E. N. Bernard of the Joint Tsunami Rescarch [ffort, Mational Oceanic and Atmospheric Administration, Hawaif Institute of Geophysics, and of George Carrier of Harvard University.

This study vias performed for the Energy Research and Development Administration Tamarín Committee.

\section{LITERATURE CITED}

1. Charles L. Plader, "Detonations Near the Water Surface," Los Alamos Sctentific Laboratory report LA-4958 (1972).

2. James D. Kershner and Charles L. Plader, "2DE: A Two Dimenstonal Continuous Eulerian Hydrodynamic Cude for Computing Multicomponent React ive Hydrodynamic Problems." Los Alamos Scient if ic Laboratory report LA-4932 (1972). 
3. Bobby G. Craig, "Experimental Observations of Underwater Detonattons Nlear the hater Surface," Los Alamos Scientific Laboratory report LA-5548-MS (1974).

4. Charles L. Hader, "Munerical Simulation of Tsunamis," Hawaif Institute of Geophy:sics report III G-73-3 and Joint Tsunami Research Effort report INMA-JTRE-85 (1973), also J. Physical Oceanography 4. 74-82 (1974).

5. C. H. Hirt, frivate comunication.

6. J. E. Welch, F. H. Harlow, J. P. Shannen and B. J. Daly, "The MAC Method," LOs Alamos Scientific Laboratory report LA-i42S (1S65).

7. R. K. C. Chan and R. L. Street, J. Comput. Phys. 6, 68-94 (1970).

8. B. D. Nichols and C. W. Hirt, J. Comput. Phys. 8 434-448 (i971).

9. Anthony A. Amsden and Francis H. Harlow, "The SiAC Method: A Humerical Technique for Calculating Incompressible fluid Flowis," Los Alamos Scientific Laboratory report LA-4370 (.970), aiso J. Comput. Phys. 6 322-325 (1970).

10. Anthony A. Amsden, "llumertcal Calculation of Surface Haves: A Modifted ZurI Code with Surface Particles and Partial Cells," Los Alamos Scientific Laboratory report LA-5146 (1973). 
Fig. 1. Two-dimensional Eulerian compressible hydrodynamic calculations of a $1.27-\mathrm{cm}$ radius 9404 explosive sphere Initiated at its center and immersed to a depth of 1.59 $\mathrm{cm}$. The pressure contour interval is 20 kilobars and the velocity contour interval is $0.05 \mathrm{~cm} /$ usecond. The position of mixed cells (9404-water, 9404-air, water-air, or 9404-waterair) is shown with an " $X$ " plotting symbol.

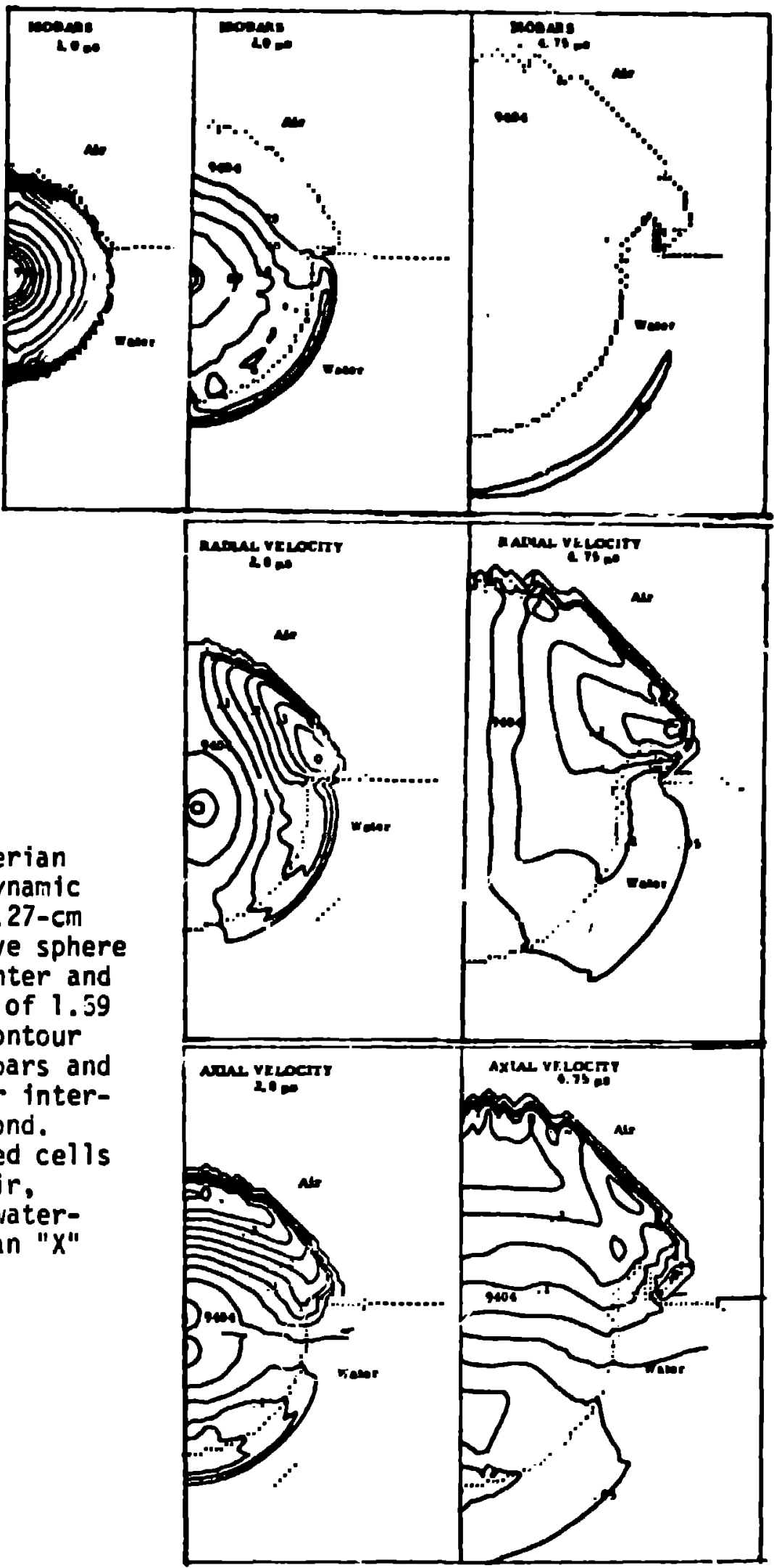




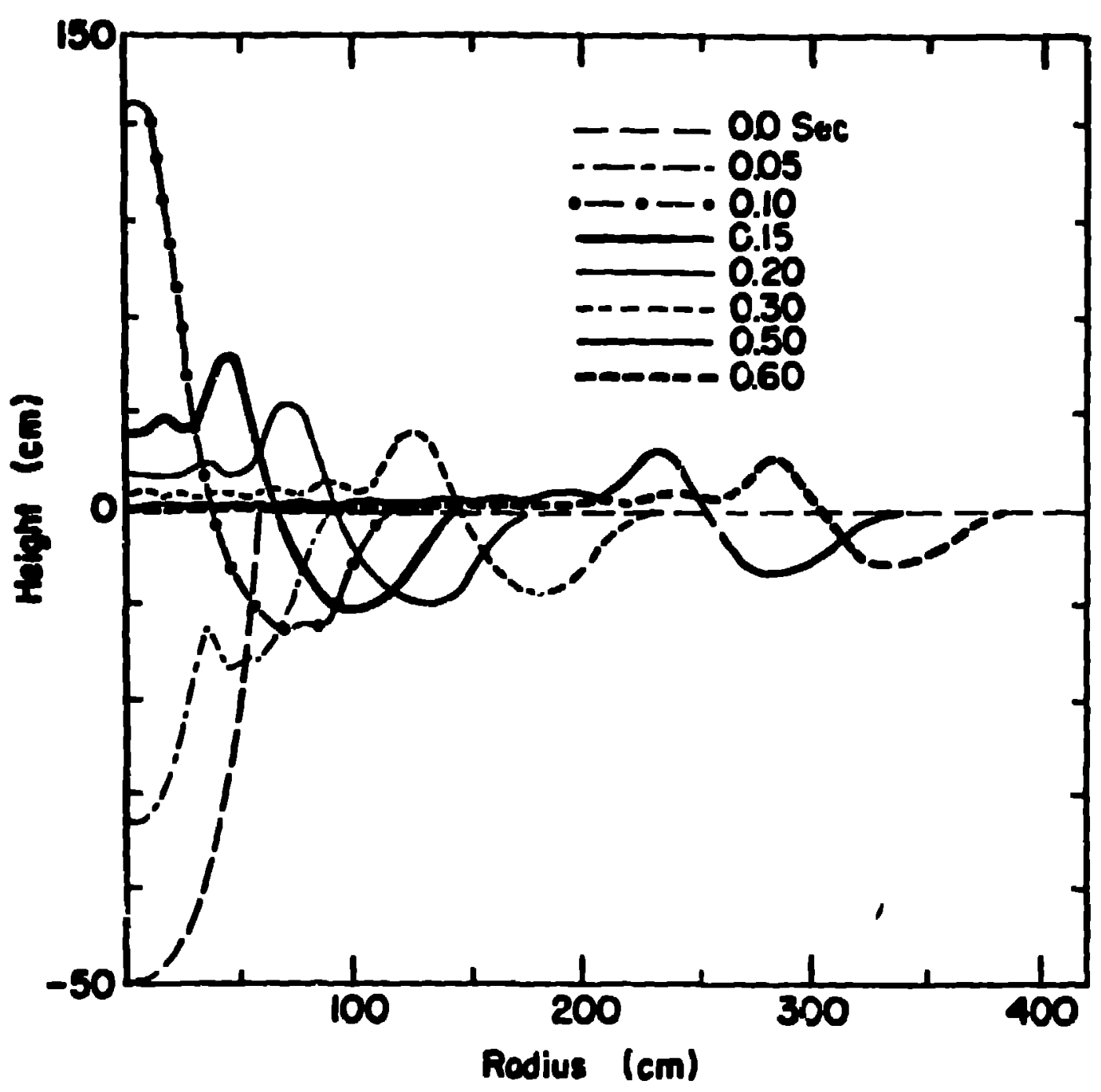

Fig. 2. The computed surface height vs racicis at various times of the collapse of a 50-cm radius hole in three meters of water using the shallow water-long wave model and che SWAY code. 


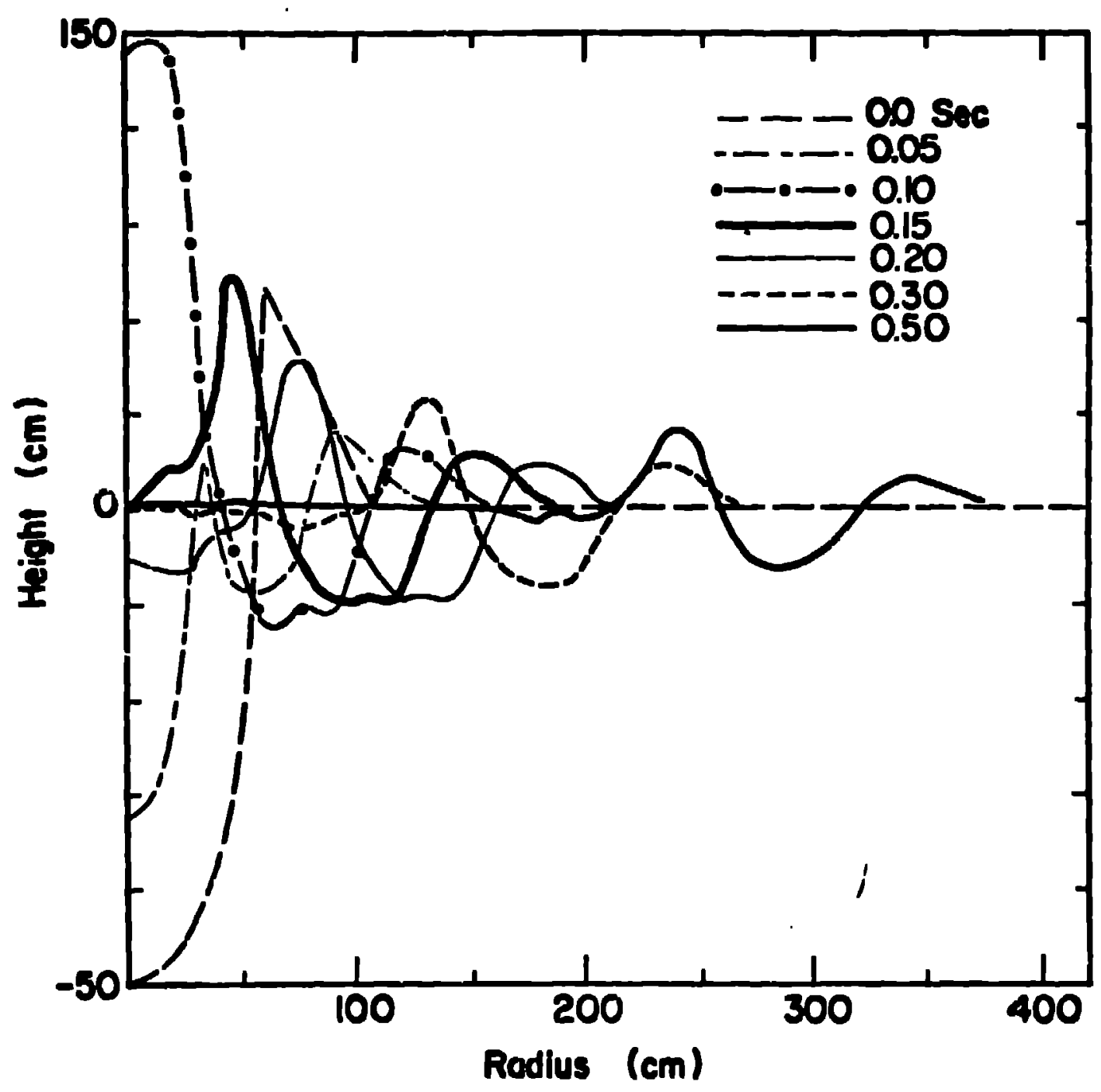

Fig. 3. The calculated surface height vs radius at various times of the collapse of a $50-\mathrm{cm}$ radtils hole with a trlangular $11 \mathrm{p}$ using the shallow water-long wave model and the SHAN code. 

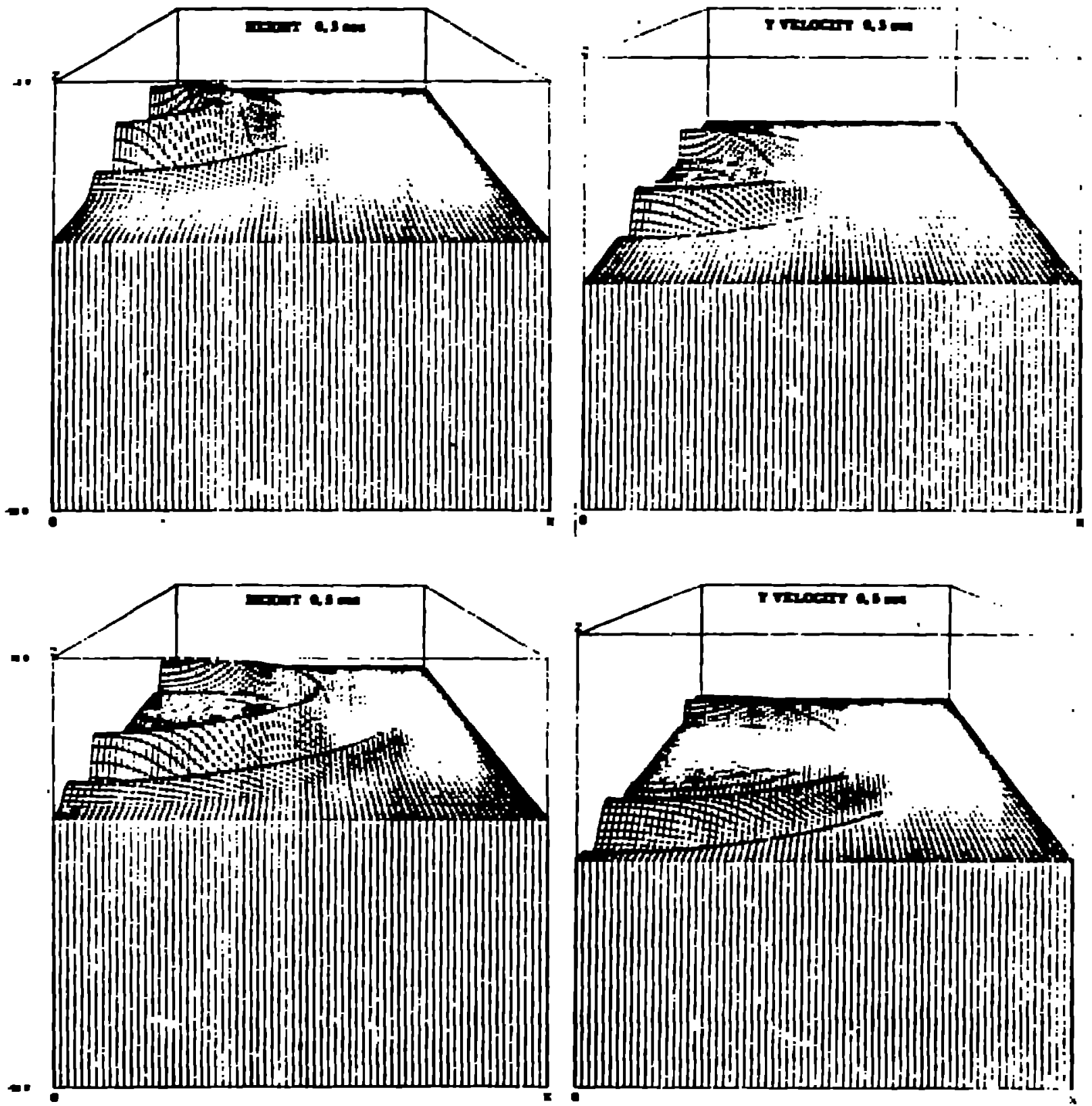

F1g. 4. Picture plots 1.1 three dinenstons of the surface profiles and the velocity in the $Y$ direction proftles at 0.3 and 0.5 seconds for the calculation described in Fig. 3. 


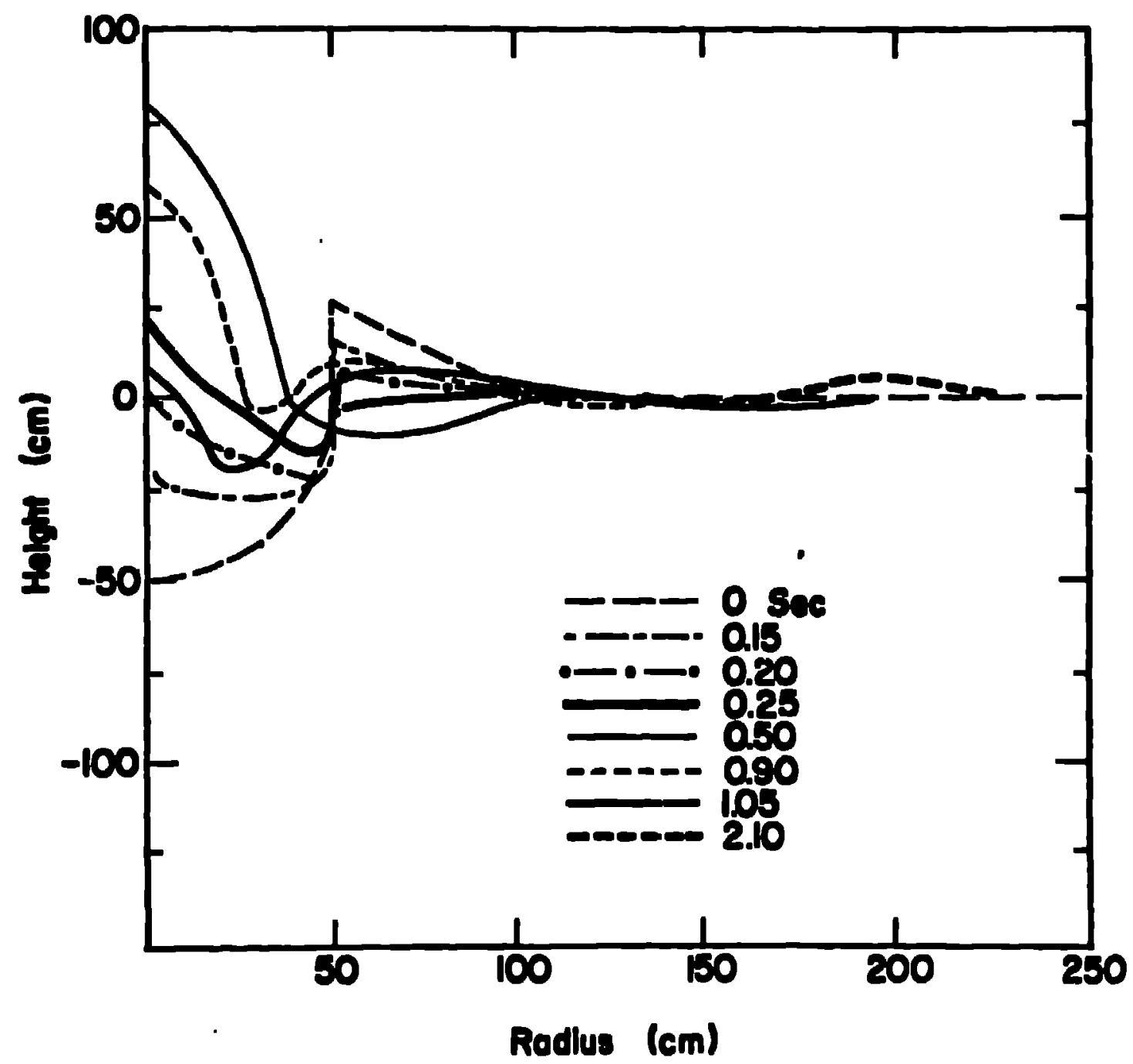

F1g. 5. The calculated surface helght vs radius at various $t$ imes of the collapse of a $50-\mathrm{cm}$ radius hole with a triangular lip using the Incompressible Navter-Stokes model and the ZUNI code. 